\title{
Evidence of Linkages between Patient Safety and Person-Centred Care in the Maternity and Obstetric Context-An Integrative Review
}

\author{
Elisabeth Severinsson ${ }^{*}$, Megumi Haruna ${ }^{2}$, Maria Rönnerhag1,3, Anne Lise Holm", \\ Britt S. Hansen ${ }^{1,5}$, Ingela Berggren ${ }^{3}$ \\ ${ }^{1}$ Centre for Women's, Family \& Child Health, Department of Nursing and Health Sciences, \\ Faculty of Health and Social Sciences, University College of Southeast-Norway, Kongsberg, Norway \\ ${ }^{2}$ Department of Midwifery and Women's Health, Division of Health Sciences \& Nursing, \\ Graduate School of Medicine, The University of Tokyo, Tokyo, Japan \\ ${ }^{3}$ Department of Health Sciences, University West, Trollhättan, Sweden \\ ${ }^{4}$ Department of Health Sciences, Western Norway University of Applied Sciences, Haugesund, Norway \\ ${ }^{5}$ Department of Health Studies, Faculty of Social Sciences, University of Stavanger, Stavanger, Norway \\ Email: *elisabeth.severinsson@usn.no
}

How to cite this paper: Severinsson, E., Haruna, M., Rönnerhag, M., Holm, A.L., Hansen, B.S. and Berggren, I. (2017) Evidence of Linkages between Patient Safety and Person-Centred Care in the Maternity and Obstetric Context-An Integrative Review. Open Journal of Nursing, 7, 378-398. https://doi.org/10.4236/ojn.2017.73030

Received: January 22, 2017

Accepted: March 17, 2017

Published: March 20, 2017

Copyright (C) 2017 by authors and Scientific Research Publishing Inc. This work is licensed under the Creative Commons Attribution International License (CC BY 4.0).

http://creativecommons.org/licenses/by/4.0/

\begin{abstract}
The aim was to evaluate the current state of knowledge pertaining to patient safety and its link to person-centred care. The international relevance of patient safety has expanded, as have the models of person-centred care. Inspired by this new trend, we collated and summarized the literature for evidence of the two topics. The study was guided by Russell, Whittemore and Knafl's integrative review framework. An electronic database search was conducted for relevant articles from 2005 to 2016. This review was conducted in accordance with the Preferred Reporting Items for Systematic Reviews and Meta-Analyses guidelines. The structure and process of the evaluation of the evidence are described and the findings interpreted by means of a thematic synthesis. One theme emerged: trustful, safe communication in the relationship between the patient, family members and healthcare professionals and two domains; safety culture and multidisciplinary capacity building. The dominant dimension in the safety culture domain is respectful communication, which implies sharing experiences that lead to a sense of control during labour and birth and is related to the women's feeling of personal capacity. The dominant dimensions in the multidisciplinary capacity building domain are collaborative teamwork, coordination and risk management, knowledge sharing and patient-centred communication. In conclusion, to enhance patient safety, it is necessary to develop patient-focused, evidence-based skills and guidelines as well as a supportive organization. Due to their interaction with patients, midwives' communication competence on the part of midwives is essential for supporting the birth
\end{abstract}


and fulfilling the women's needs and expectations.

\section{Keywords}

Communication, Integrative Review, Midwifery, Nursing, Patient Safety, Person-Centred Care, Maternity, Obstetric Care

\section{Introduction}

Internationally, patient safety (PS) has become a major concern in healthcare [1]. A focus on person-centred care, patient participation and PS strategies is of the utmost importance. PS is defined as the prevention of errors associated with healthcare, thereby, constituting an essential component of quality care [2]. The WHO [3] designed an implementation guide to improve the quality of care provided to women giving birth. Learning about adverse events and near-misses is essential for enhancing maternity and obstetric care [4]. A recently published review reveals that effective communication and learning from adverse events are important. Healthcare professionals' and patients' perspectives on ethical conflicts, blame and responsibility, medication errors, lack of trust and involvement should be explored [3]. This is in accordance with the WHO [5] recommendation that PS should focus on the use of quality improvement methods. Many latent and active factors at individual and system level interact to cause PS incidents. Therefore, an integrated approach to PS is necessary for maintaining quality of care. Person-centred care has been advocated as a way to improve PS [6]. Patient involvement is essential for ensuring safety. Levels of engagement can improve the relationship between healthcare professionals, patients and families in the context of person-centred care, for example, shared decision-making [7] [8] and self-management [9]. Research on person-centred care and related concepts such as person-centredness [10], patient-centred care [11], patient-close care and patient focus has grown rapidly [12], in different contexts, e.g., mental health [10], medical wards [13] and obstetric care [14]. Systematic development of a PS culture is necessary because inadequate quality of care leads to human suffering [15]. In their qualitative study of midwifery staff perceptions of safety culture, Currie and Richens [16] argue that all staff members should be given the authority to report accidents, incidents, near-misses and safety concerns. In addition, the importance of communication between healthcare providers [17], improving relationships between patients and professionals [18] [19] as well as continuity of care [20] is described in several studies.

The role of patients in their own safety has been explored in a recent review [21]. The results revealed that existing evidence was related to medication rather than patients' capability and willingness to be involved. An investigation of the patient's role in terms of her/his rights is recommended [21]. Despite these recommendations, patients are not receiving appropriate care. Therefore, to improve the field of maternity and obstetric care, a better understanding of the strategies to 
reduce health risks should be developed.

There is some evidence that person-centred care may impact positively on patient satisfaction [22]. When defining person-centred nursing McCormack and McCance [23] (p. 472) presented four constructs: prerequisites, which concern the attributes of the nurse; the care environment, which means the context in which care is delivered; person-centred processes, which focus on delivering care through a range of activities; and expected outcomes, which are the results of effective person-centred nursing.

Starfield [24] reported that patient-centred care generally refers to interaction during visits and that the benefits may be episode oriented with focus on the management of diseases, especially comorbidity and the use of coding systems that reflect professionally defined conditions. In her research Starfield [24] states that patient-centred care should be complemented with person-centred care. However, some negative aspects have been reported in relation to nurses' views of the restructuring of healthcare, as it was found that it changed their professional roles and disrupted their relationships with patients and colleagues [25].

According to the Cochrane Collaboration literature, there are no accepted definitions of patient-centred care [22]. A concept analysis of patient-centred care revealed several attributes: holistic, individualized, respectful and empowering [26]. These authors stated that based on empirical evidence, the benefits of patient-centred care are improved quality of care, increased satisfaction with healthcare and enhanced health outcomes. A narrative review and synthesis revealed that the three core elements of patient-centred care are patient participation and involvement, the relationship between the patient and the healthcare professional, and the context in which the care is provided [11]. The review comprised $60 \mathrm{pa}-$ pers related to health policy, medical, and nursing literature. These components are of interest because our intention is to explore the linkages between PS and person-centred care in the maternity and obstetric care context. The present study is a part of a larger international research project on Patient Safety in Obstetric and Maternity Care, which is theoretically based on the WHO [1] [3] [5] recommendations.

\section{Aim}

The aim of the review was to evaluate the current state of knowledge pertaining to PS and its link to person-centred care. The review question was: What is the evidence of the relationship between PS and person-centred care in the maternity and obstetric context?

\section{Search Methods}

\subsection{Design}

This integrative review adhered to the guidelines for systematic reviews [27] [28]. The approach involved identifying, selecting and synthesizing studies with diverse methodologies and designs from a variety of sources in order to provide a more comprehensive understanding of healthcare phenomena [28]. The first task was 
to identify a set of distinct descriptions of PS and person-centred care from the literature. Second, the integrative review was performed in five stages: 1) problem formulation, i.e., the aim of the review, 2) literature search, i.e., the search methods including the databases employed, search terms and outcome, 3) evaluation of data, i.e., data extraction and quality appraisal, 4) data analysis, i.e., data abstraction and 5) interpretation and presentation of results, i.e., thematic analysis and synthesis [27] (p. 1). Thirdly, a series of propositions regarding the pattern of linkages between PS and person-centred care deduced from the selected papers was interpreted, resulting in a theme, domains and dimensions. Fourth, we compared the expected theory pattern with previous research. Finally, we ensured that the review was conducted in accordance with the preferred reporting items for systematic reviews (PRISMA) guidelines [29].

\subsection{Search Strategy and Search Terms}

Searches were conducted in online databases (CINAHL, Academic Search Premier, Webb of Science, Maternity and Infant Care, Ovid Nursing and ProQuest) from 2005 to 2016. We searched for articles that included (Major Heading (MH) "Patient Safety+") or "patient safety" and (MH "Patient Centred Care") or "patient centred care" or "people-centred health services" or "people-centred healthcare" or "people-centred health services" and (MH "Obstetric Care+") or "obstetrical care" or "maternal health services" or (MH "Nurse-Midwifery Service") or (MH "Midwifery+") or "midwifery". We also searched peer reviewed articles for (MH "Patient Safety+"), and ("Patient" or "Person" or "People N2cent*") and ("matern" or "obstetr" or "pregnan" or "childbirth*”). In the third search we combined the above with "Communication+" or "communication" or (MH "Leadership") or (MH “Feedback”) or (MH “Collaboration”).

\subsection{Inclusion and Exclusion Criteria}

We included articles that met the following criteria: original research studies with a qualitative and/or quantitative design, published in English language as well as a maternity and obstetric context. We required articles to specifically use the term "patient safety" and excluded those that did not. Likewise, due to the range of overlapping definitions of person-centred care we only selected articles that referred to person-centred care or similar, such as patient-centred care. Studies were excluded that did not include the maternity care context. Guidance statements, review articles, educational development and study protocols were also excluded. However, the reviews that were of interest in relation to our aim were read and included in the Introduction and Discussion. This constitutes the second stage of the integrative review [27] (p. 1).

\subsection{Search Outcome}

We identified 414 articles before eliminating duplicates. Two additional articles were identified through other sources such as a manual search of reference lists, thus we screened 416 abstracts. 386 articles were excluded and a full text review 
was conducted on the remaining 30 , after which an additional 18 articles were excluded. A manual search took place in August 2016, which resulted in one article. Finally, a total of 12 articles met the inclusion criteria and were included in the quality appraisal and synthesis. Figure 1 summarizes the results of the database search, abstract and full text screening as well as the inclusion/exclusion criteria, i.e., the third stage of the data evaluation [27] (p. 1).

An overview of the included studies is presented in Table 1.

\subsection{Quality Appraisal}

The quality appraisal was conducted by applying the Critical Appraisal Skills Programme (CASP) [30], tools to determine the validity and reliability of the studies, as well as the relevance of each study to our review question. The CASP Cohort Study Checklist was used to assess the quality of the quantitative studies, while the CASP Qualitative Checklist was employed to assess the qualitative studies. For mixed-methods studies both qualitative and quantitative components of the study checklists were used. To describe the quality of evidence we used the following terms: "high quality" i.e., few limitations, "moderate quality" i.e., some criteria not met, and the "low quality", indicating serious limitations with only a few or no criteria being met or failure to adequately address the criteria. We did not use a checklist for the theoretical studies. Elliott and Thompson's [31] descriptions of quantitative research appreciation were employed to assess the methodological quality of the individual studies. Differences in scores were resolved by discussion, thus no study was excluded due to low quality.

\subsection{Data Abstraction}

We adapted the template presented by Long and Godfrey [32] to assess the quality of the empirical and theoretical studies. The rationale for choosing this template was that we were not only interested in whether the study was of high quality, but also wanted to understand whether the findings were relevant to the maternity and obstetric care context, thereby maximizing our understanding of the contextual meanings. The data from the articles were extracted by the first author (E.S.). In the third stage, four components were focused on: 1) the phenomenon studied: core elements of PS, 2) design/methodology, data collection, analysis and sample, 3) context: setting in which the care was delivered, core theoretical elements of person-centred care (or its variants, such as patient-centredness, patient-close care or patient focus, midwifery-led care, women-centred care) and 4) policy and practice implications. Each of the included articles was reviewed and evaluated independently by three of the authors. Finally, two of the authors independently appraised the Tables illustrating the results. Table 2 presents the fourth stage, i.e., data analysis of the integrative literature review process [27] (p. 1).

\subsection{Synthesis}

We were interested in the linkages between culture and context. The thematic analysis was followed by a process of interpretation, i.e., the fifth stage leading to the 
Articles identified through database search CINAHL $(\mathrm{n}=342)$, Academic Search Premier $(n=26)$, Webb of Science $(n=100)$,

Maternity and Infant Care $(\mathrm{n}=5)$,

Ovid Nursing $(\mathrm{n}=18)$ ProQuest $(\mathrm{n}=23)$

$$
(n=414)
$$

Additional articles identified through other sources $(n=2)$
Abstracts screened

using selection criteria $(n=416)$

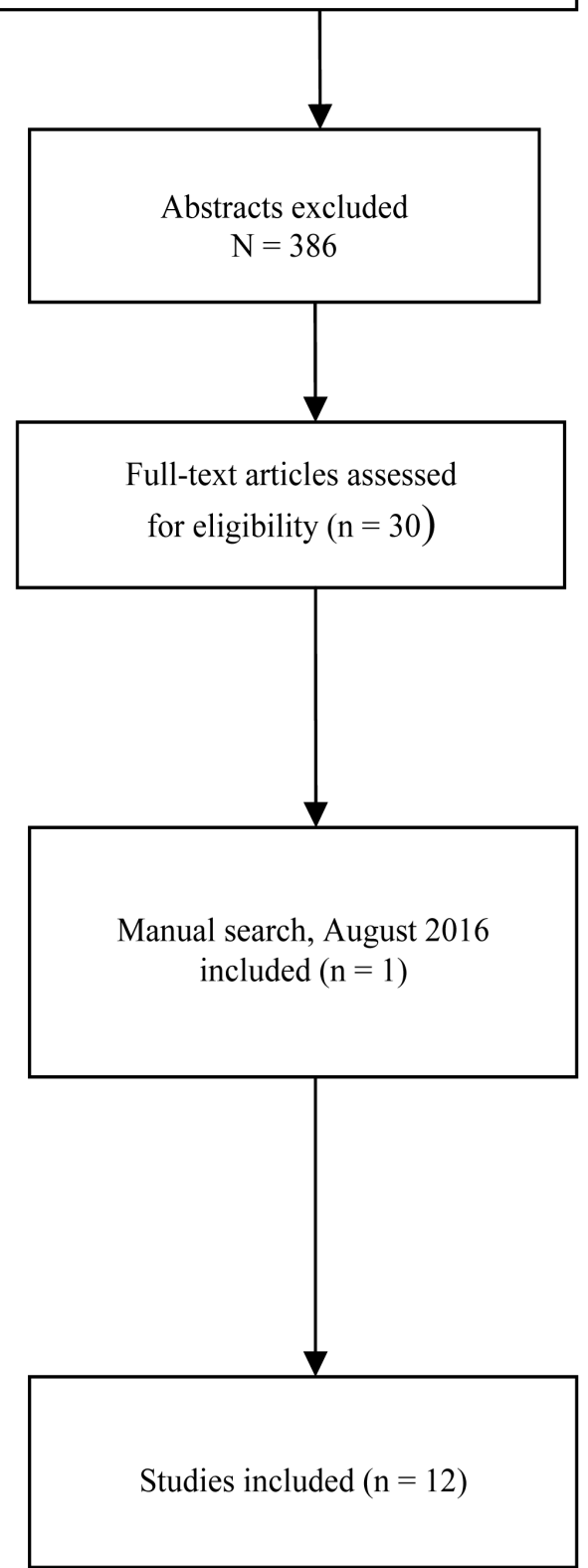

Articles excluded

-duplicates

-proceedings

-national reports on health safety

-policy guidelines

-conference papers

Full-text articles excluded, with reasons

-not related to maternity care context

-not related to patient safety -educational development -study protocol

Figure 1. Data search using the PRISMA [29] flow diagram. 
Table 1. Characteristics of the included studies.

\begin{tabular}{|c|c|c|c|}
\hline \multirow[b]{2}{*}{ Authors, year and country Design } & Methods & Measurements & \multirow[b]{2}{*}{ Key Findings } \\
\hline & $\begin{array}{c}\text { Data collection, } \\
\text { sample and analysis }\end{array}$ & Patient safety/quality & \\
\hline $\begin{array}{l}\text { Martijn et al. } 2013 \text { [33] } \\
\text { The Netherlands } \\
\text { Mixed-methodology } \\
\text { Cohort }\end{array}$ & $\begin{array}{l}1000 \text { patient records } \\
\text { Retrospective: content } \\
\text { analysis } \\
\text { Prospective incident } \\
\text { reporting, type of incident, } \\
\text { cause, actual harm, and } \\
\text { probability of serious } \\
\text { harm or death. } \\
\text { Expert postgraduate } \\
\text { midwives reviewed safety } \\
\text { incidents using the } \\
\text { Prevention and Recovery }\end{array}$ & $\begin{array}{l}\text { Self-reported patient safety } \\
\text { assessment instrument } \\
\text { communication } \\
\text { problems; patient risk } \\
\text { assessment based on } \\
\text { obstetric history, health } \\
\text { status, lifestyles factors, } \\
\text { psychosocial problems, number } \\
\text { of contacts during care, calls } \\
\text { for help due to medical } \\
\text { emergency, whether or } \\
\text { not a safety incident had }\end{array}$ & $\begin{array}{l}\text { Of the } 1000 \text { patient records } \\
\text { involving contacts, } 85 \text { contained } \\
\text { incidents, of which } 25 \text { were } \\
\text { found to have had a significant } \\
\text { effect on the patient. } \\
\text { The majority of incidents } \\
\text { found in the patients' records } \\
\text { concerned treatment and } \\
\text { organizational factors }\end{array}$ \\
\hline
\end{tabular}

Sexton et al. 2006

[34]

USA

Cross-sectional survey

Wagner et al. 2011 [35] USA

Cohort comparative (prospective) Intervention study:

1) Evidence-based protocols,

2) Formalized team training with emphasis on communication,

3) Standardization of electronic foetal monitoring with required documentation of competence,

4) A high-risk obstetrical emergency simulation programme, and

5) Dissemination of an integrated educational programme among all healthcare providers

\section{Hoang \& Quynh 2012 [36] \\ Australia}

Mixed-method approach
Eleven adverse outcome measures $\mathrm{N}=217-1731$

Cross-sectional survey questionnaire $(\mathrm{n}=210)$ and semi-structured interviews $(\mathrm{n}=22)$
Self-reported measurement of teamwork climate, perceptions of management, stress recognition and working conditions

Self-reported instruments were used to measure the impact of the perinatal safety initiative (PSI) to evaluate and decrease adverse events and improve obstetric outcomes. A modified adverse outcome index (MAOI) was used in addition to patients' perceptions of teamwork and commitment to patient safety. The questions were 'Would you recommend the institution?" and

"Did the staff work together?". Finally, staff perceptions of safety were assessed by using questions from the Safety Culture Climate Survey

Self-reported instrument on preferences for different models of intrapartum care. Hospital (conventional) care, Midwifery-led care, and Planned homebirth. Interviews included questions on views of travel time to safe delivery, safety, distance from hospital and delivery type
Perceptions of the teamwork climate in the labour and delivery context are affected by the environment and the role within the team.

For example, the caregivers need to feel supported and be enabled to report, ask question and speak up comfortably.

Conflicts should be resolved and nurses and physicians should collaborate. Good teamwork was also associated with lower levels of caregiver burnout from their work. Finally, the teamwork climate related more to perceptions of adequate staffing levels than to workload

The MAOI decreased significantly to $0.8 \%$ from $2 \%(\mathrm{p}<0.0004)$ which was maintained throughout the two year of intervention period. Significant decreases over time were found for rates of return to the operating room and birth trauma was found. A significant improvement was found in staff perceptions of safety $(p<0.0001)$, in patient perceptions of whether staff worked together $(\mathrm{p}<0.0001)$, in the management and in the documentation of abnormal foetal heart rate tracings, and the documentation of obstetric haemorrhage

The women preferred to give birth in a hospital setting despite having to travel for two hours. Midwifery-led care with one hour travel time was the second most preferred model 


\author{
Iida et al. 2011 [37] Japan \\ Cross-sectional \\ survey (retrospective)
}

\begin{abstract}
A package of questionnaires $\mathrm{N}=591$
\end{abstract}

Lyndon et al. 2015 [38] San Francisco USA

Theoretical approach based on empirical collaborative research

Larkin et al. 2012 [39] Ireland Qualitative descriptive study

Raab et al. 2013 [40] USA

Theoretical approach based on previous empirical studies

Collins 2008

USA [41]

Theoretical approach

Sarrechiaet al. 2012 [42] Belgium

A descriptive study using qualitative methods

Hamman et al. 2009 [43] USA

Mixed-methods

Case study design

White et al. 2005 [44] USA

Retrospective analysis
Expert professionals from four organizations that care for women during labour and birth

Interviews, five focus-groups, $\mathrm{n}=25$

Cross-sectional survey Questionnaire $\mathrm{n}=210$ Intervention: team training, simulation, safety walk rounds. Implementation of collaborative processes

Review of claims involved in malpractice cases reported to $\mathrm{IOM}^{3)}$

Examination of the content of care pathway of documenting care, content analysis. The content was compared with 40 evidence-based of Map of Medicine files

Simulation-based team training interviews

90 consecutive obstetrics and gynecology-related internal review of files
Self-completed retrospective questionnaire; A researcher-developed women-centred care questionnaire, Labour Agentry Scale, Maternal

Attachment Questionnaire and researcher-developed

Care Satisfaction Scale

\section{Expert opinion}

No information about the instruments used in previous studies in the group's collaborative research on safety issues in labour and delivery teams

A qualitative analysis process was developed by focusing on expectations, opinions, experiences and emotions

Self-reported

Safety Attitudes Questionnaire

Evidence-based key interventions

\section{Electronic foetal monitoring education}

Identifying latent threats to patient safety

Identifying action, events, and environmental circumstances that appeared to contribute to the event.
Women who delivered at birth centres rated women-centred care highly and were satisfied with the care they received compared to those who gave birth at clinics and hospitals. This was related to respectful communication during antenatal checkups and the ontinuity of care by midwives

Patient safety requires mutual accountability; individuals, teams, healthcare facilities, and professional associations have a shared responsibility for creating and sustaining environments of mutual respect and engaging in highly reliable perinatal care

Three themes were identified; "getting started", "getting there" and "consequences". Control was an important element in childbirth experiences. Women felt alone and unsupported

Increased collaboration can improve patient outcomes and provider satisfaction.

An organization's leadership and culture will affect the outcome of collaborative efforts.

Collaboration is a process that optimizes perinatal patient safety.

Chain of communication

Multidisciplinary teamwork increases communication and can reduce the number of adverse events

An important variation in the use of evidence-based key interventions within the obstetric care pathway applied to the baby and mother

Improving communication, access to blood products and technical competences

Fifty percent of cases were associated with in-patient obstetrics. Factors that may have contributed to adverse events were identified in $78 \%$ of cases, while

$31 \%$ were associated with apparent communication problems 
overall main theme, key aspects or domains, as well as sub-themes [27] (p. 1). The selected articles were compared, grouped and qualitatively summarized in relation to the review question. The five authors read the articles, extracted terms or descriptions and validated the first draft Table 2. The interpretation of aspects of PS was based on the theoretical view of PS presented by the WHO [1] [3] [5]. For interpretation of components of the contexts we used the core elements of patient-centred care; patient participation and involvement, the relationship between the patient and healthcare professional, and the context in which care is provided [11] (p. 4).

\section{Results}

\subsection{Search Results}

In total, 416 abstracts were screened, resulting in the inclusion of 30 full texts, peer-reviewed articles. Following quality assessment, the final sample comprised 12 articles on PS and person-centred care. The characteristics of the 12 articles are presented in Table 1. Of these, nine were empirical [33] [34] [35] [36] [37] [39] [42] [43] [44] and three applied a theoretical approach [38] [40] [41]. The studies were conducted in different countries, i.e., the Netherlands [33], the USA [34] [35] [38] [40] [41] [42] [43] [44], Australia [36], Japan [37] and Ireland [39].

\subsection{Summary of Quality Assessment}

The designs comprised mixed-methods [33] [36] [43], a cross-sectional survey [34] [36] [37], a cohort study (prospective, i.e., implying the forward direction of the research question and retrospective, i.e., meaning that when the study is planned, all or part of the data have already been collected [33] [35] [44], a qualitative descriptive study [42], review of documents, i.e., a theoretical approach [38] [41] as well as an intervention case study [43] Table 1. The information about selection bias was unclear in terms of the representativeness of the population. Some studies failed to report confounding factors related to recruitment or analysis. Two studies were document analyses of files pertaining to medical errors or adverse events, outcomes and closed claims [41] [44].

Only two studies addressed the appropriateness of the sample size. One study had a very low response rate [36]. Most of the studies used correlational, regression statistical analyses and descriptive statisticsas well as $\chi^{2}$ tests [36]. The study by Iida et al. [37] used the Pearson correlational coefficient to examine the relationship between variables and applied a multiple regression analysis to compare women's perception of women-centred care and their satisfaction with care during pregnancy. Convergent validity of the scale scores was measured by correlations with external teamwork related items [34]. The study by Wagner et al. [35] used logistic regression. In summary, the most common weaknesses of the included studies related to design, sampling and analysis. The quality of each relevant study is reported in Table 2 . 
Table 2. Evaluative overview and quality assessment of the selected articles adapted from the Long and Godfrey [32] template ${ }^{1)}$.

\begin{tabular}{|c|c|c|c|c|c|}
\hline $\begin{array}{l}\text { Authors } \\
\text { and year }\end{array}$ & $\begin{array}{l}\text { Phenomena studied: } \\
\text { core elements } \\
\text { of } \text { PS }^{*} \text { studied }\end{array}$ & $\begin{array}{l}\text { Context: where the } \\
\text { care is delivered }\end{array}$ & $\begin{array}{c}\text { Context: core } \\
\text { theoretical } \\
\text { elements of PCC }\end{array}$ & Policy and practice implications & $\begin{array}{l}\text { Quality } \\
\text { assessment } \\
\text { score }^{2)}\end{array}$ \\
\hline $\begin{array}{c}\text { Martijn et al. } \\
2013 \text { [33] }\end{array}$ & $\begin{array}{l}\text { Safety culture } \\
\text { Type of incidents }\end{array}$ & $\begin{array}{c}\text { Primary care } \\
\text { midwifery practices }\end{array}$ & Midwifery-led care & $\begin{array}{l}\text { Adherence to practice guidelines } \\
\text { for patient risk assessment, } \\
\text { better implementation of } \\
\text { interventions with regard to risk } \\
\text { factors and better availability of } \\
\text { midwives during birthing }\end{array}$ & M \\
\hline $\begin{array}{l}\text { Sexton et al. } \\
2006[34]\end{array}$ & $\begin{array}{c}\text { Safety culture } \\
\text { Teamwork climate }\end{array}$ & $\begin{array}{c}\text { Hospital care, } \\
\text { labor and delivery units }\end{array}$ & $\begin{array}{l}\text { Theory of safety culture. } \\
\text { Culture understood as } \\
\text { artifacts, values and } \\
\text { assumptions that make } \\
\text { an organization distinct }\end{array}$ & $\begin{array}{l}\text { To explore links to clinical } \\
\text { and operational outcomes }\end{array}$ & $\mathrm{H}$ \\
\hline $\begin{array}{c}\text { Wagner } \\
\text { et al. } 2011 \\
{[35]}\end{array}$ & $\begin{array}{l}\text { Adverse events } \\
\text { Perinatal safety }\end{array}$ & $\begin{array}{l}\text { Hospital care, } \\
\text { obstetrics ward }\end{array}$ & $\begin{array}{c}\text { A multicomponent } \\
\text { model: evidence-based } \\
\text { protocols, team training, } \\
\text { fetal monitoring, } \\
\text { simulation program, } \\
\text { educational program }\end{array}$ & $\begin{array}{l}\text { Multicomponent safety } \\
\text { initiatives in the healthcare } \\
\text { system are necessary } \\
\text { to improve PS }\end{array}$ & $\mathrm{H}$ \\
\hline $\begin{array}{c}\text { Hoang \& } \\
\text { Quynh } 2012 \\
{[36]}\end{array}$ & $\begin{array}{l}\text { Access to } \\
\text { safety care }\end{array}$ & $\begin{array}{l}\text { Hospital (conventional) } \\
\text { care, midwifery-led care } \\
\text { and planned homebirth }\end{array}$ & $\begin{array}{l}\text { Three different } \\
\text { models of } \\
\text { intrapartum care }\end{array}$ & $\begin{array}{l}\text { Women's preferences } \\
\text { should be taken into account } \\
\text { when planning for type } \\
\text { of delivery. }\end{array}$ & $\mathrm{L}$ \\
\hline $\begin{array}{c}\text { Iida et al. } \\
2011 \\
{[37]}\end{array}$ & $\begin{array}{l}\text { Safety, sense of control } \\
\text { during labor and birth } \\
\text { Communication and } \\
\text { satisfaction with care }\end{array}$ & $\begin{array}{l}\text { Three different types of } \\
\text { health facility; birth centres, } \\
\text { clinics and hospitals }\end{array}$ & $\begin{array}{l}\text { Women-centred } \\
\text { care }\end{array}$ & $\begin{array}{l}\text { Healthcare providers should } \\
\text { consider the positive correlation } \\
\text { between women-centred care } \\
\text { and women's perceptions of } \\
\text { satisfaction, in addition to } \\
\text { continuity of care and } \\
\text { respectful communication }\end{array}$ & $\mathrm{H}$ \\
\hline $\begin{array}{c}\text { Lyndon et al. } \\
2015[38]\end{array}$ & Safety culture & $\begin{array}{l}\text { Intrapartum care } \\
\text { Perinatal care }\end{array}$ & $\begin{array}{l}\text { Patient-centred } \\
\text { communication }\end{array}$ & $\begin{array}{l}\text { Approaches for } \\
\text { improving communication }\end{array}$ & NI \\
\hline $\begin{array}{c}\text { Larkin et al. } \\
2012[39]\end{array}$ & $\begin{array}{l}\text { Women's physical safety } \\
\text { Risk management }\end{array}$ & $\begin{array}{c}\text { Hospital units } \\
\text { Rural and city hospital }\end{array}$ & Conventional care & $\begin{array}{l}\text { Quality of maternity services } \\
\text { must encompass recognition } \\
\text { of psychological and emotional } \\
\text { well-being alongside } \\
\text { physical safety }\end{array}$ & $\mathrm{H}$ \\
\hline $\begin{array}{l}\text { Raab et al. } \\
2013[40]\end{array}$ & Safety culture & $\begin{array}{c}\text { Perinatal care } \\
\text { Three academic facilities }\end{array}$ & Collaborative model & $\begin{array}{l}\text { Changing culture requires } \\
\text { administrative support and } \\
\text { role modeling, staff involvement } \\
\text { and sustainment of the } \\
\text { desire to change } \\
\text { Sharing experiences debriefing }\end{array}$ & NI \\
\hline $\begin{array}{l}\text { Collins } \\
2008[41]\end{array}$ & $\begin{array}{l}\text { Safety culture } \\
\text { Teamwork } \\
\text { Medical errors } \\
\text { Communication }\end{array}$ & Perinatal hospital units & $\begin{array}{c}\text { Multidisciplinary } \\
\text { team approach Uniform } \\
\text { patient care strategies } \\
\text { Patient-relevant } \\
\text { information } \\
\text { Collaborative approach } \\
\text { Decision-making }\end{array}$ & $\begin{array}{c}\text { Team training, rapid } \\
\text { response teams } \\
\text { Interdisciplinary electronic } \\
\text { fetal monitoring course } \\
\text { Crew resource } \\
\text { management approach } \\
\text { Uniformity of practice } \\
\text { Discussion of system failures }\end{array}$ & NI \\
\hline
\end{tabular}




\section{Continued}

\begin{tabular}{|c|c|c|c|c|c|}
\hline $\begin{array}{l}\text { Sarrechia } \\
\text { et al. } 2012 \\
{[42]}\end{array}$ & $\begin{array}{c}\text { Communication } \\
\text { Coordination of care } \\
\text { Multidisciplinary teams }\end{array}$ & $\begin{array}{l}17 \text { care pathway for } \\
\text { normal delivery } \\
\text { All organization that } \\
\text { submitted pathway } \\
\text { documents consented to } \\
\text { inclusion in the study. } \\
\text { One member of the research } \\
\text { team rendered the pathway } \\
\text { documents anonymous }\end{array}$ & $\begin{array}{l}\text { Donabedian's } \\
\text { paradigm, i.e., the } \\
\text { relationship between } \\
\text { the structure, process } \\
\text { and outcome of care } \\
\text { Knowledge-sharing } \\
\text { networks }\end{array}$ & $\begin{array}{l}\text { The pathway documents } \\
\text { should be more standardized, } \\
\text { reviewed by peers and checked } \\
\text { for the inclusion of all } \\
\text { interventions before } \\
\text { used in daily practice }\end{array}$ & $\mathrm{H}$ \\
\hline $\begin{array}{l}\text { Hamman } \\
\text { et al. } 2009 \\
{[43]}\end{array}$ & $\begin{array}{l}\text { Risks and failures } \\
\text { in the healthcare } \\
\text { organization } \\
\text { Safety culture }\end{array}$ & $\begin{array}{c}\text { Four in situ simulations } \\
\text { were conducted in a } \\
\text { community hospital, } \\
\text { obstetric ward }\end{array}$ & Team training & $\begin{array}{l}\text { Results from clinical simulations } \\
\text { in an operational healthcare } \\
\text { setting can help identify and } \\
\text { resolve threats to patient safety }\end{array}$ & $\mathrm{L}$ \\
\hline $\begin{array}{l}\text { White et al. } \\
2005 \text { [44] }\end{array}$ & $\begin{array}{l}\text { Risk management } \\
\text { Communication }\end{array}$ & Hospital & $\begin{array}{l}\text { Respectful approach, } \\
\text { good communication, } \\
\text { safe boundaries and } \\
\text { careful communication }\end{array}$ & $\begin{array}{l}\text { Analysis of claims files may } \\
\text { help identify opportunities } \\
\text { for improvement. Computerized } \\
\text { physicians order entry and } \\
\text { teamwork tools may improve } \\
\text { information flow and help } \\
\text { prevent miscommunication }\end{array}$ & $\mathrm{H}$ \\
\hline
\end{tabular}

${ }^{\star}$ Patient Safety $=$ PS, ${ }^{*}$ Person-Centred Care $=$ PCC or its variants, such as patient-centredness, patient-closer care or patient focus, midwifery-led care, women-centred care. ${ }^{1)}$ Long and Godfrey [32]. ${ }^{2}$ Assessment quality: $\mathrm{H}=$ high i.e., most of the criteria are fulfilled, $\mathrm{M}=$ moderate i.e., some of the criteria are not fulfilled, and L $=$ low i.e., few or none of the criteria are not fulfilled. ${ }^{3}$ Institute of Medicine = IOM. ${ }^{4}$ Theoretical approach, expert opinion [38], implementation of programme [40] [41].

\subsection{Evidence Related to Key Components of Long and Godfrey's Evaluation Criteria}

Criterion No.1: the core elements of PS. All articles reporting presented PS presented patient safety culture aspects, thereby contributing to knowledge and understanding of the problems inherent in practice. Criterion No.2: design/methodology, data collection, analysis and sample are described in Table 1. Criterion No.3; context: setting in which the care was delivered, core theoretical elements of person-centred care. The context/settings presented were primary care midwifery practices [33], hospital labour and delivery units [34] [36] [39] [40] [41] [44], and an obstetric ward [35]. The core theoretical elements of person-centred care were midwifery-led care [33] [36], women-centred care [37], safety culture theory [34], a multicomponent model including evidence-based protocols, team training, foetal monitoring simulation and an educational programme [35] [43], patient-centred communication [38], a collaborative model [40], and a multidisciplinary team approach [41]. Two studies focused on the relationship between the structure, process and outcome of care with reference to Donabedian's paradigm [42] and a respectful approach, good, and careful communication and safe boundaries [44]. The third area centred on the sampling strategy adopted Table 1 . The samples varied between 22 - 4700 subjects. In some studies, "Why were these informants or events chosen?" To answer the research question was not explicitly reported nor was the relevance of key events to the study aims.

Criterion No.4, policy and practice implications, the outcome criteria informing 
the study i.e., "What counts as 'success' or a beneficial effect?" It was possible to interpret guidelines for patient risk assessment [33], to improve PS multicomponent safety initiatives in the healthcare system [35] [39], enhance approaches to communication [38], share experiences by debriefing [40], team training [41], standardized documentation [42] and analysis of claim files to identify opportunities for improvement [44]. In summary, the perspectives of patients [33] [36] [37] [39] and professionals [34] [35] [38] [40] [41], were addressed. The quality total score of each relevant study is reported in Table 2. Overall, we found a range of research designs employing qualitative and quantitative approaches. They were rated as high $(\mathrm{n}=6)$, moderate in quality $(\mathrm{n}=1)$ and low quality $(\mathrm{n}=2)$.

The selected articles described the core elements of PS, with emphasis on medical, technical and caring aspects. The person-centred care models are determined by the quality of interactions between the patient, family members and healthcare professionals, in addition to communication skills, shared understanding, decision making and emotional support. The contextual aspects of maternity and obstetric care interact with various intervention strategy components to improve PS and are enhanced by competence outcomes and the linkages to person-centred care.

\subsection{Evidence of the Linkages between Patient Safety and Person-Centred Care in Maternity and Obstetric Care}

One theme was revealed: Trustful, safe communication in the relationship between the patient, family members and healthcare professionals. Two domains; Safety culture and Multidisciplinary capacity building, emerged in the results. There were six dimensions related to the first domain, namely: Values, beliefs and trust, Respectful communication, Sense of control of labour and birth, Patient involvement, Sharing experiences and Continuity of care, while the second domain, was based on the following five dimensions: Collaborative work, Knowledge sharing, Teamwork, networking and accountability, Coordination and risk management and Patient-centred communication Table 3.

Domain 1: All included studies reported aspects of Safety culture. The study by Martijn et al. [33] presented evidence that availability, patient risk assessment and communication were problematic domains. Cultural aspects such as values, beliefs and trust in the relationship between the patient and healthcare professionals were reported [34] [36] [40]. Respectful communication was described in three studies [37] [41] [43]. The sub-theme sense of control of labour and birth was found in four studies [33] [35] [37] [39]. Patient involvement was included in the theme of safety culture in six studies [33] [36] [37] [38] [42] [44]. Eight of the studies highlighted the importance of sharing experiences [33] [35] [36] [37] [38] [40] [42] [44] while one also mentioned continuity of care [37].

Domain 2: The theme Multidisciplinary capacity building was based on the results from all included studies. This theme consisted of five sub-themes, all related to multidisciplinary work: Collaborative work [34] [36] [40] [41] [43], Knowledge sharing [43] [44] Teamwork, Networking and Accountability [34] [38] [40] [41] 
Table 3. The synthesis of linkages between patient safety and person-centred care.

\begin{tabular}{|c|c|c|}
\hline \multicolumn{3}{|c|}{ Theme: Trustful, safe communication in the relationships between the patient, family members and healthcare professionals } \\
\hline Domain & Key dimensions & Sources \\
\hline \multirow[t]{6}{*}{ 1. Safety culture } & Values, beliefs and trust & [34] [36] [40] \\
\hline & Respectful communication & [37] [41] [43] \\
\hline & Sense of control of labour and birth & [33] [35] [37] [39] \\
\hline & Patient involvement & [33] [36] [37] [38] [42] [44] \\
\hline & Sharing experiences & [33] [35] [36] [37] [38] [40] [42] [44] \\
\hline & Continuity of care & {$[37]$} \\
\hline \multirow[t]{5}{*}{ 2. Multidisciplinary capacity building } & Collaborative work & [34] [36] [40] [41] [43] \\
\hline & Knowledge sharing & {$[43][44]$} \\
\hline & Teamwork, networking and accountability & {$[34][38][40][41][43][44]$} \\
\hline & Coordination and risk management & [33] [35] [36] [39] [42] [43] [44] \\
\hline & Patient-centred communication & [35] [37] [38] [41] [42] \\
\hline
\end{tabular}

[43] [44]. Factors related to the healthcare organization, and leadership were Coordination and Risk Management [33] [35] [36] [39] [42] [43] [44] and finally, Patient-centred Communication was interpreted as involving Capacity Building [35] [37] [38] [41] [42].

\section{Discussion}

There are few studies on the theoretical and clinical importance of understanding the relationship between PS and person-centred care. To address this gap we developed an integrative review to evaluate the current state of the evidence. Findings from this review advance our knowledge and have significant theoretical and clinical implications. The key feature of PS and person-centred care in the maternity and obstetric context is trustful safe communication in the relationship between the patient, family members and healthcare professionals, based on two domains; Safety culture comprising six dimensions and Multidisciplinary capacity building consisting on five dimensions.

Series of propositions regarding the pattern of linkages between PS and person-centred care were identified from the selected papers, which can inform clinical assessment and interventions as they highlight the fact that communication and/or miscommunication may pose a risk to PS in the maternity and obstetric context. Similar to previous empirical studies of PS [4], this review provides strong evidence of the need for good communication between healthcare professionals and patient. If the communication process does not include the sharing of meaningful information, it may result in poor quality, uncertainty and conflict. Notably, these findings expand previous research by presenting two perspectives of PS and person-centred care, namely safety culture and multidisciplinary capacity building. The clinical implications of the findings are therefore noteworthy. The main component in the safety culture domain is respectful communication, where 
the sharing of experiences leads to a sense of control during labour and birth as it relates to the women's sense of personal capacity. According to Yu et al. [2], other prerequisites for PS are patient involvement and continuity of care, which prevent errors. Thus, the second major finding was that the midwives' communication competences are essential due to the necessity of interacting with patients to support the birth and meet the women's needs and expectations. This is confirmed by the study by Renfrew et al. [45] that highlights respect, communication, knowledge and understanding for facilitating care that is tailored to women's circumstances and needs. The third major finding was that collaborative teamwork, coordination and risk management, knowledge sharing and patient-centred communication constitute an important part of the multidisciplinary capacity building domain. This finding is consistent with the WHO's [1], PS theory comprising five domains: Leadership and management, Patient and public involvement, Safe evidence-based clinical practices, Safe environment and Lifelong learning.

\subsection{Communication}

Not surprisingly, communication appears in both domains. However, the two dimensions differ in that patient-centred communication can be interpreted as a professional attitude on the part of midwives that includes sharing information and incident reporting. This is in line with Mendes and Ventura's [46] research on verbal and non-verbal communication, the ability to listen and interpret feedback, in addition to awareness of safety issues. The systematic review by Ward and Armitage [47] emphasizes the patient's voice as a key element of PS development and management.

Despite the necessity of involving patients in their own safety, the efforts to promote involvement are not focused upon. The relationship between the birth environment and midwifery practice should be explored with focus on a safe and satisfying birth. Foureur et al. [48] suggest studying the impact of design on communication in maternity care settings and developing a conceptual model based on the literature and understanding of design, communication, stress and care models. This is an innovative starting point for a deeper understanding of the complexity of birth and the range of disciplines necessary for safe and effective maternity care. In line with the theory of PS, person-centred care may improve quality and shared decision-making by transforming and developing decisionmaking through the engagement model [49] to improve health outcomes, suggesting that a new patient-centred implementation model is required. This framework focusing on the core components of evidence-based decision making through the engagement model links PS and person-centred care and has the potential to go beyond maternity care and influence other clinical areas. Central to this model is the women's active involvement in decision-making [49]. The findings from this review are in line Lyndon et al. [50], who demonstrated that effective multiprofessional communication in maternity care is respectful, clear, direct, and explicit. The Lyndon et al. [50] highlighted of the importance of improving communication by building it on an infrastructure of respect, attentiveness, 
collaboration, and competence, which is in agreement with our findings.

Our findings demonstrate the need for improved communication processes in the area of care planning. Quality and safety are informed by women's experiences [51] Different levels of engagement can be discussed in relation to the importance of communication: in direct care, i.e., the relationship between healthcare professionals, patients and families; on the organizational level to enable patients and their family members to influence the way the organization provides care; and in community healthcare to make it possible for patients and their family members to influence the health or healthcare strategies of public agencies [2].

Overall, this review contributes novel and important knowledge that deepens the understanding of how an organization functions or fails. It also highlights the need for system change [52], arguing that to change our behaviour within a system, we have to change the way we think about the system per se, the way knowledge is created and how we become involved in the process of knowledge translation [52] (p. 226). The Safety Model described by Macchi et al. [15] is based on the anticipation of undesired events and measures to ensure safe functioning. The emphasis of the non-linear model's emphasis on the organization and its dynamics calls into question linear causal thinking to explain accidents, while supporting the normal functioning of the organization in combination with the prevention of incidents and accidents. Processes to develop PS are implemented across the organization and take the organization's characteristics into account, such as communicating advice to protect against risks and for organizational development [15]. The safe management systems are embedded in the organization's culture. Entwistle and Watt [53] (p. 36) emphasize that person-centred care can be understood in terms of a single guiding idea that involves recognizing and cultivating patients' personal capabilities. Despite the differences between the definitions and characterizations, person-centred care can be related to the broad overarching ethical idea that patients should be "treated as persons" [53] (p. 29). The authors suggest the capability approach as a guiding idea, including behaviours such as respect, compassion, responsiveness to subjective experiences, and support for autonomy, thus, the intrinsic value of person-centred care. This approach constitutes a broad normative framework for the evaluation and assessment of individual well-being [54].

Qualitatively enhancing the understanding of a phenomenon by illuminating its meanings may lead to healthcare professionals adopting a more holistic approach to care. An integrated team and the way team members work together will influence communication about safety. Finally, directly involving team members in person-centred care will facilitate safe care.

\subsection{Limitations of This Review, and Suggestions for Future Research}

This review makes valuable and unique contributions to deepening the understanding of the links between PS and person-centred care. However, the findings should be interpreted in the light of some limitations. CASP [30] was the assess- 
ment tool used for quality appraisal of observational analytic (cohort, cross sectional and case-control) [55] studies and also for the qualitative appraisal as well. As suggested by Long and Godfrey [32] (p. 184), we adapted some parts of the evaluation tool to assess the quality of the studies and reflect the uniqueness of the associated paradigm Table 1 and Table 2 . When developing their evaluation tool the authors focused on the following questions: The conceptual or theoretical framework: i.e., "In what way does this study contribute to knowledge theory and/or practice?", the contextual aspects related to the setting in which the study was undertaken, i.e., "Why this setting?", "Is it appropriate in order to examine the research question?" and "Is sufficient detail provided about the setting?", the nature of the sampling strategy adopted, i.e., "Why were these informants or events chosen?" and "Are key events appropriate given the study aims?", and finally the outcome criteria i.e., "What counts as 'success' or has a beneficial effect and over which time periods?" In the synthesis of the findings the reviewers were cautious when extracting the domains and dimensions from the empirical and theoretical studies. Interpretative methods were used to synthesize and integrate the findings. Essential components of the linkages between PS and person-centred care were identified. The concept of person-centred care is used interchangeably with patient-centred care, although they could vary slightly and thereby provide different information that we might have missed. However, the authors are experienced in several areas of nursing practice and have numerous years of research experience in the contexts of nursing, midwifery, and public health and health sciences. In addition, they collaborated closely and discussed the quality and the content of the findings. A further limitation is that the quality appraisal or assessment tools used are dependent on the study design and not all questions were relevant to the individual studies. In addition, the authors' understanding of research design and critique as well as knowledge of the difficulty involved in interpreting the design employed should be taken into account. Further empirical research is needed to understand the linkages between PS and person-centred care.

\section{Conclusion}

We conclude that there are several linkages between PS and person-centred care in the maternity and obstetric context. Healthcare professionals have an important role in delivering safe person-centred care and require knowledge, leadership, academic supervision, mentorship and financial resources to maintain quality of care and PS.

\section{Acknowledgements}

The authors would like to thank Monique Federsel for proofreading the English language and the specialized librarian at the University College of Southeast Norway for valuable help with the electronic search for articles.

\section{Funding Statement}

We acknowledge that the study was supported by the Japan Society for Promo- 
tion of Science (ID No.S15190) and awards to Professor Elisabeth Severinsson for her work at the Department of Midwifery and Women's Health at The University of Tokyo. The study was supported by a grant from the University College of Southeast Norway.

\section{Conflicts of Interest}

All authors declare that there are no conflicts of interest with regard to this study.

\section{Author Contributions}

Elisabeth Severinsson was the project supervisor. She co-conceptualised and designed the study, drafted the initial manuscript, and approved the final manuscript. All authors contributed to the data analysis and interpretation of the results. All authors provided feedback on the draft manuscript and approved the final version. They all adhered to the criteria pertaining to roles and responsibilities in the research process recommended by the ICMJE

(http://www.icmje.org/recommendations)

\section{References}

[1] World Health Organization (WHO) (2016) Patient Safety Assessment Manual. Geneva.

http://apps.who.int/iris/bitstream/10665/249569/1/EMROPUB_2016_EN_18948.pd f?ua $=1$

[2] Yu, A., Flott, K., Chainani, N., Fontana, G. and Darzi, A. (2016) Patient Safety 2030. NIHR Patient Safety Translational Research Centre at Imperial College London and Imperial College Healthcare NHS Trust, London.

[3] World Health Organization (WHO) (2013) Safe Childbirth Checklist Implementation Guide: Improving the Quality of Facility-Based Delivery for Mothers and New Borns. WHO Press, World Health Organization, Geneva. http://apps.who.int/iris/bitstream/10665/199177/1/9789241549455_eng.pdf?ua=1

[4] Severinsson, E., Haruna, M., Rönnerhag, M. and Berggren, I. (2015) Patient Safety, Adverse Events and Near-Misses in Obstetric Care-A Systematic Literature Review. Open Journal of Nursing, 5, 1110-1122.

https://doi.org/10.4236/ojn.2015.512118

[5] World Health Organization (2009) The WHO Patient Safety Curriculum Guide for Medical Schools. WHO Press, World Health Organization, Geneva. http://www.who.int/patientsafety/education/curriculum/download/en/index.html

[6] Bucknall, T., Hutchinson, M., Botti, M., McTier, L., Rawson, H., Hewitt, N.A., McMurray, A., Marshall, A.P., Gillespie, B.M. and Chaboyer, W. (2016) Engaging Patients and Families in Communication across Transitions of Care: An Integrative Review Protocol. Journal of Advanced Nursing, 72, 1689-1700.

https://doi.org/10.1111/jan.12953

[7] Holm, A.L., Lyberg, A., Berggren, I. and Severinsson, E. (2014) Shared DecisionMaking after Implementation of the Chronic Care Model (CCM) - An Evaluative Approach. Open Journal of Nursing, 4, 824-835.

https://doi.org/10.4236/ojn.2014.412088

[8] Holm, A.L., Berland, A.K. and Severinsson, E. (2016) Older Patients' Involvement 
in Shared Decision-Making-A Systematic Review. Open Journal of Nursing, 6, 170-185. https://doi.org/10.4236/ojn.2016.63018

[9] Holm, A.L., Lyberg, A., Berggren, I., Lassenius, E. and Severinsson, E. (2013) Older Person's Lived Experiences of Depression and Self-Management. Issues of Mental Health, 34, 757-764.

[10] McCormack, B., Karlsson, B., Dewing, J. and Lerdal, A. (2010) Exploring PersonCentredness: A Qualitative Meta-Synthesis of Four Studies. Scandinavian Journal of Caring Sciences, 24, 620-634. https://doi.org/10.1111/j.1471-6712.2010.00814.x

[11] Kitson, A., Marshall, A., Bassett, K. and Zeitz, K. (2013) What Are the Core Elements of Patient-Centred Care? A Narrative Review and Synthesis of the Literature from Health Policy, Medicine and Nursing. Journal of Advanced Nursing, 69, 4-15. https://doi.org/10.1111/j.1365-2648.2012.06064.x

[12] Wilde-Larsson, B., Inde, M., Carlson, A., Nordström, G., Larsson, G. and Rystedt, I. (2014) Implementation of Patient-Focused Care: Before-After Effects. International Journal of Health Care Quality Assurance, 27, 594-604. https://doi.org/10.1108/IJHCQA-06-2013-0067

[13] Tobiano, G., Bucknall, T., Marshall, A., Guinance, J. and Chaboyer, W. (2015) Nurses' Views of Patient Participation in Nursing Care. Journal of Advanced Nursing, 71, 2741-2752. https://doi.org/10.1111/jan.12740

[14] Moore, J.E., Low, L.K., Titler, M.G., Dalton, V.K. and Sampselle, C.M. (2014) Mowing towards Patient-Centred Care: Women's Decision, Perceptions, and Experiences of the Induction of Labor Process. Birth, 41, 138-146.

https://doi.org/10.1111/birt.12080

[15] Macchi, L., Pietikäinen, E., Reiman, T., Heikkilä, J. and Ruuhilehto, K. (2011) Patient Safety Management: Available Models and Systems. Research Report, Helsinki. http://www.vttresearch.com/

[16] Currie, L. and Richens, Y. (2009) Exploring the Perceptions of Midwifery Staff about Safety Culture. British Journal of Midwifery, 17, 783-790. https://doi.org/10.12968/bjom.2009.17.12.45548

[17] Martijn, L., Jacobs, A., Amelink-Verburg, M., Wentzel, R., Buitendijk, S. and Wensing, M. (2013b) Adverse Outcomes in Maternity Care for Women with a Low Risk Profile in the Netherland: A Case Serious Analysis. British Medical Central Pregnancy and Childbirth, 13, 219. https://doi.org/10.1186/1471-2393-13-219

[18] Scholefield, H. (2007) Embedding Quality Improvement and Patient Safety at Liverpool Women's NHS Foundation Trust. Best Practice and Research Clinical Obstetrics and Gynaecology, 21, 593-607. https://doi.org/10.1016/j.bpobgyn.2007.02.005

[19] Lawton, R., Gardner, P. and Plachcinski, R. (2010) Using Vignettes to Explore Judgments of Patients about Safety and Quality of Care: The Role of Outcome and Relationship with the Care Provider. Health Expectations, 14, 296-306. https://doi.org/10.1111/j.1369-7625.2010.00622.x

[20] Simpson, K.R., James, D.C. and Knox, E.G. (2006) Nurse-Physician Communication during Labor and Birth: Implications for Patient Safety. Journal of Obstetric, Gynecologic and Neonatal Nursing. Clinical Issues, 35, 547-556.

https://doi.org/10.1111/j.1552-6909.2006.00075.x

[21] Severinsson, E. and Holm, A.L. (2015) Patients' Role in Their Own Safety-A Systematic Review of Patient Involvement in Safety. Open Journal of Nursing, 5, 642653. https://doi.org/10.4236/ojn.2015.57068

[22] Lewin, S., Skea, Z., Entwistle, V.A., Zwarenstein, M. and Dick, J. (2001) Interventions for Providers to Promote a Patient-Centred Approach in Clinical Consultations (Review). Cochrane Database of Systematic Reviews, No. 4, CD003267. 
$\underline{\text { http://researchonline.lshtm.ac.uk/17325/ }}$

[23] McCormack, B. and McCance, T. (2006) Development of a Framework for PersonCentred Nursing. Journal of Advanced Nursing, 56, 472-479. https://doi.org/10.1111/j.1365-2648.2006.04042.x

[24] Starfield, B. (2011) Is Patient-Centered Care the Same as Person-Focused Care? The Permanente Journal, 15, 63-69. https://doi.org/10.7812/TPP/10-148

[25] Mikesell, L. and Bromley, E. (2012) Patient Centered Nurse Averse? Nurses' Care Experiences in a 21st Century Hospital. Qualitative Health Research, 22, 1659-1671. https://doi.org/10.1177/1049732312458180

[26] Morgan, S. and Yoder, H.L. (2012) A Concepts Analysis of Person-Centered Care. Journal of Holistic Nursing, 30, 6-15. https://doi.org/10.1177/0898010111412189

[27] Russell, C. (2005) An Overview of the Integrative Research Review. Progress in Transplantation, 15, 8-13. https://doi.org/10.1177/152692480501500102

[28] Whittemore, R. and Knafl, K. (2005) The Integrative Review: Updated Methodology. Journal of Advanced Nursing, 52, 546-553. https://doi.org/10.1111/j.1365-2648.2005.03621.x

[29] Moher, D., Liberati, A., Tetzlaff, J., Altman, D.G. and The PRISMA Group (2009) Preferred Reporting Items for Systematic Reviews and Meta-Analyses: The PRISMA Statement. Annals of Internal Medicine, 151, 264-269. https://doi.org/10.7326/0003-4819-151-4-200908180-00135

[30] Critical Appraisal Skills Programme (CASP) (2013) Making Sense of Evidence. CASP, London. http://www.casp-uk.net/

[31] Elliot, D. and Thompson, D. (2007) Research Appreciation and Application. Common Quantitative Methods. In: Schneider, Z., Whitehead, D. and Elliot, D., Eds., Nursing and Midwifery Research. Methods and Appraisal for Evidence-Based Practice, Elsevier, Mosby, 103-121.

[32] Long, A. and Godfrey, M. (2004) An Evaluation Tool to Assess the Quality of Qualitative Research Studies. International Journal of Social Research Methodology, 7, 181-196. https://doi.org/10.1080/1364557032000045302

[33] Martijn, L., Jacobs, A., Massen, I., Buitendijk, S. and Wensing, M. (2013) Patient Safety in Midwifery-Led Care in the Netherlands. Midwifery, 29, 60-66. https://doi.org/10.1016/j.midw.2011.10.013

[34] Sexton, J.B., Holzmueller, C.G., Pronovost, P.J., Thomas, E.J., McFerran, S., Nunes, J., Thompson, D.A., Knight, A.P., Penning, D.H. and Fox, H.E. (2006) Variation in Caregiver Perceptions of Teamwork Climate in Labor and Delivery Units. Journal of Perinatology, 26, 463-470. https://doi.org/10.1038/sj.jp.7211556

[35] Wagner, B., Meirowitz, N., Shah, J., Nanda, D., Reggio, L., Cohen, P.B.K., Kaufmn, L., Walis, R., Bacotre, C., Lesser, M.L., Pekmezaris, R., Fleiser, A. and Abrams, K.J. (2011) Comprehensive Perinatal Safety Initiative to Reduce Adverse Obstetric Events. Journal of Healthcare Quality, 34, 6-15. https://doi.org/10.1111/j.1945-1474.2011.00134.x

[36] Hoang, H. and Le Quynh, L. (2012) Trade-Off between Local Access and Safety Considerations in Childbirth: Rural Tasmanian Women's Perspectives. Australian Journal of Rural Health, 20, 144-149. https://doi.org/10.1111/j.1440-1584.2012.01266.x

[37] Iida, M., Horiuchi, S. and Porter, S. (2012) The Relationship between Women-Centred Care and Women's Birth Experiences: A Comparison between Birth Centres, Clinics, and Hospitals in Japan. Midwifery, 28, 458-465. https://doi.org/10.1016/j.midw.2011.07.002

[38] Lyndon, A., Johnson, C.M., Bingham, D., Napolitano, P.G., Joseph, G., Maxfield, 
D.G. and O'Keeffe, D.F. (2015) Transforming Communication and Safety Culture in Intrapartum Care: A Multi-Organization Blueprint. Journal of Obstetric, Gynecologic and Neonatal Nursing, 44, 341-349.

https://doi.org/10.1111/1552-6909.12575

[39] Larkin, P., Begley, C. and Devane, D. (2012) "Not Enough People to Look after You": An Exploration of Women's Experiences of Childbirth in the Republic of Ireland. Midwifery, 28, 98-105. https://doi.org/10.1016/j.midw.2010.11.007

[40] Raab, C.A., Brown Will, S.E., Richards, S.L. and O'Mara, E. (2013) The Effects of Collaboration on Obstetric Patient Safety in Three Academic Facilities. Journal of Obstetric, Gynecologic and Neonatal Nursing, 42, 606-616. https://doi.org/10.1111/1552-6909.12234

[41] Collins, D.E. (2008) Multidisciplinary Teamwork Approach in Labor and Delivery and Electronic Fetal Monitoring Education. Journal of Perinatal Neonatal Nursing 22, 125-132. https://doi.org/10.1097/01.JPN.0000319099.82543.9f

[42] Sarrechia, M., Van Gerven, E., Hermans, L., Deneckere, S., Sermeus, W., Panella, M., Spitz, B. and Vanhaecht, K. (2012) Variations in 17 Obstetric Care Pathways: Potential Danger for Health Professionals and Patient Safety. Journal of Advanced Nursing, 69, 278-285. https://doi.org/10.1111/j.1365-2648.2012.06004.x

[43] Hamman, W., Beaudin-Seiler, B., Beaubien, J., Gullickson, A.M., Gross, A., Orizondo-Korotko, K., Fuqua, W. and Lammers, R. (2009) Using in Situ Simulation to Identify and Resolve Latent Environmental Treats to Patient Safety: Case Study Involving a Labor and Delivery Ward. Journal of Patient Safety, 5, 184-187. https://doi.org/10.1097/PTS.0b013e3181b35e6c

[44] White, A., Pichert, J., Bledsoe, S., Irwin, C. and Entman, S.S. (2005) Cause and Effect Analysis of Closed Claims in Obstetrics and Gynecology. American College of Obstetricians and Gynecologists, Women's Health Care Physicians, 5, 1031-1038. https://doi.org/10.1097/01.aog.0000158864.09443.77

[45] Renfrew, M.J., McFadden, A., Bastos, M.H., Campell, J., Channon, A.A, Cheung, F.N., Delage Silva, D.R.A., Downe, S., Kennedy, H.P., Malata, A., McCormick, F., Wick, L. and Delercq, E. (2014) Midwifery and Quality: Findings from a New Evidence-Informed Framework for Maternal and Newborn Care. The Lancet, 384, 1129-1145. https://doi.org/10.1016/S0140-6736(14)60789-3

[46] Mendes, I.A.C. and Venturs, C.A.A. (2016) Leading and Advocating for Global Competencies: A Nursing Challenge. Journal of Nursing Management, 24, 843-844. https://doi.org/10.1111/jonm.12432

[47] Ward, J.K. and Armitage, G. (2012) Can Patients Report Patient Safety Incidents in a Hospital Setting? A Systematic Review. British Medical Journal: Qualitative and Safety, 21, 685-699. https://doi.org/10.1136/bmjqs-2011-000213

[48] Foureur, M., Davis, D., Fenwick, J., Iedema, R., Forbes, I. and Homer, C. (2010) The Relationship between Birth Unit Design and Safe, Satisfying Birth: Developing a Hypothetical Model. Midwifery, 26, 520-525. https://doi.org/10.1016/j.midw.2010.05.015

[49] Moore, J.E., Titler, M.G., Low, L.K., Dalton, V.K. and Sampselle, C.M. (2015) Transforming Patient-Centered Care: Development of the Evidence Informed Decision Making through Engagement Model. Women's Health Issues, 25, 276-282. https://doi.org/10.1016/j.whi.2015.02.002

[50] Lyndon, A., Zlatnik, M. and Wachter, R.M. (2011) Effective Physician-Nurse Communication: A Patient Safety Essential for Labor and Delivery. American Journal of Obstetric Gynecology, 205, 91-96. https://doi.org/10.1016/j.ajog.2011.04.021

[51] Shaw, D., Guise, J.-M., Shah, N., Gemsell-Danielsson, K., Joseph, K.S., Levy, B., 
Wong, F., Woodd, S. and Main, E.K. (2016) Drivers of Maternity Care in High-Income Countries: Can Health Systems Support Woman-Centred Care? The Lancet, 388, 2282-2295. https://doi.org/10.1016/S0140-6736(16)31527-6

[52] Kitson, A. (2008) The Need for Systems Change: Reflections on Knowledge Translation and Organizational Change. Journal of Advanced Nursing, 65, 217-228. https://doi.org/10.1111/j.1365-2648.2008.04864.x

[53] Entwistle, V.A. and Watt, I.S. (2013) Treating Patients as Persons: A Capabilities Approach to Support Delivery of Person-Centered Care. The American Journal of Bioethics, 13, 29-39. https://doi.org/10.1080/15265161.2013.802060

[54] Robeyns, I. (2005) The Capability Approach: A Theoretical Survey. Journal of Human Development, 6, 93-114. https://doi.org/10.1080/146498805200034266

[55] Glasziou, P. and Henegan, C. (2009) A Spotter's Guide to Study Designs. EvidenceBased Medicine, 14, 37-38. https://doi.org/10.1136/ebm.14.2.37-a

Submit or recommend next manuscript to SCIRP and we will provide best service for you:

Accepting pre-submission inquiries through Email, Facebook, LinkedIn, Twitter, etc. A wide selection of journals (inclusive of 9 subjects, more than 200 journals)

Providing 24-hour high-quality service

User-friendly online submission system

Fair and swift peer-review system

Efficient typesetting and proofreading procedure

Display of the result of downloads and visits, as well as the number of cited articles

Maximum dissemination of your research work

Submit your manuscript at: http://papersubmission.scirp.org/

Or contact ojn@scirp.org 